\title{
Prognostic Value of Serum Cholinesterase in Acute Organophosphate Poisoning
}

\author{
Arun Kumar Sah ${ }^{1}$, Rajesh Kumar Mandal ${ }^{2}$ \\ ${ }^{1}$ Consultant Physician, Department of Internal Medicine, Gajendra Narayan Singh Hospital, Rajbiraj, Nepal. \\ ${ }^{2}$ Consultant Physician, Department of Internal Medicine, Bheri Hospital, Nepalgunj, Nepal. \\ Corresponding Author: Arun Kumar Sah
}

DOI: https://doi.org/10.52403/ijhsr.20220217

\begin{abstract}
Background: Organophosphorus (OP) compounds are anti acetylcholinesterase, used abundantly as pesticides and often misused as poisoning agents. Irreversible inhibition of cholinesterase enzymes is attributed to the serious clinical outcomes in these patients. This study aims to identify the relationship between the serum cholinesterase (SChE) activity and outcome.

Material and Methods: A descriptive cross-sectional study conducted in the Department of Internal Medicine of Bir Hospital, Kathmandu from July 2019 to December 2019. 50 patients of OP poisoning were studied. Laboratory investigations including SChE activity were performed and their management and their outcomes were recorded and analyzed by using statistical package for social sciences (SPSS) version 20.

Results: Poisoning was more predominant in young adults of the age group of 15 to 35(68\%) years. Most common compound used for poisoning was chlorpyriphos $50 \%$ + cypermethrin $5 \%$ followed by dichlorvos 85\% and cypermethrin. Among 50 cases 48 cases were discharged after successful management while 2 cases expired. No significant relation between initial serum level of acetylcholinesterase and outcome was observed in this study with p- value $>0.05$. Significant relation between initial serum acetylcholinesterase level, duration of hospital stay, atropinization dose and hospital arrival time from ingestion of poison was found with $p$ - value of $<0.05$.

Conclusion: There was a significant correlation between SCH levels and total atropinization dose, duration of hospital stay and hospital arrival time. However no significant correlation was found for the clinical outcome and need of mechanical ventilator.
\end{abstract}

Keywords: organophosphorus poisoning, serum acetylcholinesterase, cholinesterase

\section{INTRODUCTION}

Acute

poisoning

organophosphorus (OP) is a major global health concern with thousands of deaths every year. World health organization (WHO) estimates three million pesticides poisoning events annually with about 300,000 deaths per year. ${ }^{1}$

Organophosphorus (OP) toxicity is mainly because of irreversible inhibition of acetylcholinesterase (AchE) leading to accumulation of acetylcholine (Ach) and overactivation of cholinergic receptors at neuromuscular $(\mathrm{N}-\mathrm{M})$ junctions and in the autonomic and central nervous systems $(\mathrm{CNS}){ }^{2}$

Muscarinic features include excessive salivation, lacrimation, urination, diarrhea, gastrointestinal cramps, emesis, blurred vision, miosis, bradycardia, and wheezing. ${ }^{3}$ Nicotinic effects include muscle fasciculations, cramping and weakness while respiratory depression, seizures, and unconsciousness are the consequence of central nervous system toxicity. ${ }^{4}$ Clinical diagnosis of OP poisoning depends on evidence of organophosphorus exposure, compatible clinical features, serum 
acetylcholinesterase level and improvements of the signs and symptoms after administration of atropine. ${ }^{1,2}$

RBC cholinesterase level is a sensitive indicator but not readily available and difficult to estimate. ${ }^{1}$ Although, not validated, Serum acetylcholinesterase level is continuously being used as an indicator of severity in OP poisoning. Thus, this study was intended to validate serum acetylcholinesterase as a prognostic marker of severity (in the form of mortality, atropinization dose of atropine, need of mechanical ventilator and total duration of hospital stay) in patient with acute OP poisoning.

\section{MATERIAL AND METHODS}

This study was an observational cross-sectional study conducted in the Department of Internal Medicine of National Academy of Medical Sciences (NAMS), Bir hospital between July 2019 to December 2019. The ethical clearance for the research activity was obtained from the Institutional Review Board of NAMS, Reg. No. 870/076/77.

50 cases with history of OP poisoning or clinical features suggestive of OP poisoning were enrolled in the study. Blood sample was taken by the on duty doctor for estimation of serum cholinesterase level. Serum acetylcholinesterase level was measured by colorimetric method. The final outcome of the patients was recorded. The statistical analysis was done by Statistical Package for Social Sciences version 20 software. Univariate correlation between these with Serum cholinesterase level were evaluated using Pearson correlation coefficient and chi-square test and Fisher's exact test. $\mathrm{P}$ value less than 0.05 was considered to be significant.

\section{RESULTS}

A total of 50 patients of OP poisoning were enrolled in the study and followed from the date of admission till the final outcome in the medical wards of Bir hospital. Among the total cases 22(44\%) were male and $28(56 \%)$ were female. The age of patients ranges from 15 to 65 years. Maximum number of poisoning was in the age group of 15 to 35years (68\%) followed by $(24 \%)$ in the 36 to 50 age group. The female cases were more in the age group of 15-35 years while results were reversed in the age group of 51-65 years with male predominance. (Table 1.)

Table 1. Age vs Sex distribution

\begin{tabular}{|c|c|c|c|}
\hline \multirow[t]{2}{*}{ Age group } & \multicolumn{2}{|l|}{ SEX } & \multirow[t]{2}{*}{ Total $(\%)$} \\
\hline & Male & Female & \\
\hline $15-35$ & 13 & 21 & $34(68)$ \\
\hline $36-50$ & 6 & 6 & $12(24)$ \\
\hline $51-65$ & 3 & 1 & $4(8)$ \\
\hline & 22 & 28 & $50(100)$ \\
\hline
\end{tabular}

Majority of the cases (84\%) were married and $16 \%$ were unmarried. Housewives, students and businessmen were the most common group of patients in our study with $38 \%, 16 \%$ and $16 \%$ respectively followed by farmers $16 \%$ and shopkeepers 10\%. Salivation (90\%), bronchorrhoea $(78 \%)$, crepitations $(82 \%)$ were the most common presenting features. Other signs and symptoms present were urinary incontinence (48\%), diarrhea (36\%), miosis (22\%), neck muscle weakness, cyanosis $(18 \%)$ and seizure $(10 \%)$. (Table 2).

Table 2. Distribution of signs and symptoms

\begin{tabular}{|l|l|l|}
\hline Signs and symptoms & Yes & No \\
\hline Miosis & $11(22 \%)$ & $39(78 \%)$ \\
\hline Diarrhoea & $18(36 \%)$ & $32(64 \%)$ \\
\hline Bronchorrhoea & $39(78 \%)$ & $11(22 \%)$ \\
\hline Urinary incontinence & $24(48 \%)$ & $26(52 \%)$ \\
\hline Lacrimation & $14(28 \%)$ & $36(72 \%)$ \\
\hline Salivation & $45(90 \%)$ & $5(10 \%)$ \\
\hline Crepitation & $41(82 \%)$ & $9(18 \%)$ \\
\hline Bradycardia & $24(48 \%)$ & $26(52 \%)$ \\
\hline Cyanosis & $9(18 \%)$ & $41(82 \%)$ \\
\hline Muscle fasciculation & $7(14 \%)$ & $43(86 \%)$ \\
\hline Tachycardia & $0(0 \%)$ & $50(100 \%)$ \\
\hline Seizure & $2(4 \%)$ & $48(96 \%)$ \\
\hline Confusion & $7(14 \%)$ & $43(86 \%)$ \\
\hline Neck muscle weakness & $9(18 \%)$ & $41(82 \%)$ \\
\hline
\end{tabular}

Most common compound used for poisoning was chlorpyriphos $50 \%$ +cypermethrin $5 \%$ followed by dichlorvos $85 \%$ and cypermethrin. Other compounds used were malathion and triazophos +deltamethrin. In this study only $18 \%$ of patients reached hospital within 1-5 hours 
after ingestion of OP compounds. Majority of them, 54\% cases reached hospital between 6-10 hours. 20\% reached late between 11-15 hours and 4(8\%) cases reached the hospital after 15 hours.

Table 3. Acetyl cholinesterase level category

\begin{tabular}{|c|c|c|}
\hline AChE Level (U/L) & No. of patients & Percent \\
\hline \begin{tabular}{l|l} 
& $1751-8500$ (Normal) \\
\cline { 2 - 2 }
\end{tabular} & 30 & 60.0 \\
\hline $700-1750$ (Mild) & 14 & 28.0 \\
\hline 350-700 (moderate) & 2 & 4.0 \\
\hline$<350$ (severe) & 4 & 8.0 \\
\hline Total & 50 & 100.0 \\
\hline
\end{tabular}

The mean serum acetylcholinesterase was 2977.86 U/L (mean S.D.+/-317.34U/L). There were no significant relation between initial presenting signs and symptoms and initial acetylcholinesterase. (Table 3)

Maximum number of cases $24(48 \%)$ got atropinized with $5-25 \mathrm{ml}$ of atropine followed by $15(30 \%)$ cases by $25-50 \mathrm{ml}$ of atropine. However $7(14 \%)$ of cases needed $>75 \mathrm{ml}$ for atropinization. (Table:4). The mean atropinization dose was $35.44 \mathrm{ml}$ (mean S.D. +/-4.35 ml). There was significant relation between initial serum acetylcholinesterase level and the dose of atropinization with $\mathrm{p}$ - value of $<0.05$.

Table 4. AChE_Category vs Atropinization dose

\begin{tabular}{|c|c|c|c|c|c|c|}
\hline \multirow{2}{*}{\multicolumn{2}{|c|}{ AChE_Category }} & \multicolumn{4}{|c|}{ Atropinization dose (ml) } & \multirow[t]{2}{*}{ Total } \\
\hline & & $5-25$ & $26-50$ & $51-75$ & $>75$ & \\
\hline \multirow[t]{2}{*}{ Normal } & Count & 22 & 7 & 0 & 1 & 30 \\
\hline & AChE_Category & $73.3 \%$ & $23.3 \%$ & $0.0 \%$ & $3.3 \%$ & $100.0 \%$ \\
\hline \multirow[t]{2}{*}{ Mild } & Count & 2 & 5 & 3 & 4 & 14 \\
\hline & $\begin{array}{l}\% \text { within } \\
\text { AChe_Category }\end{array}$ & $14.3 \%$ & $35.7 \%$ & $21.4 \%$ & $28.6 \%$ & $100.0 \%$ \\
\hline \multirow[t]{2}{*}{ moderate } & Count & 0 & 2 & 0 & 0 & 2 \\
\hline & AChE_Category & $0.0 \%$ & $100.0 \%$ & $0.0 \%$ & $0.0 \%$ & $100.0 \%$ \\
\hline \multirow[t]{2}{*}{ severe } & Count & 0 & 1 & 1 & 2 & 4 \\
\hline & AChE_Category & $0.0 \%$ & $25.0 \%$ & $25.0 \%$ & $50.0 \%$ & $100.0 \%$ \\
\hline \multirow[t]{2}{*}{ Total } & Count & 24 & 15 & 4 & 7 & 50 \\
\hline & AChE_Category & $48.0 \%$ & $30.0 \%$ & $8.0 \%$ & $14.0 \%$ & $100.0 \%$ \\
\hline
\end{tabular}

Need of mechanical ventilator during the entire course of treatment was considered as one of vital interventions during the study. Among total cases, 1 case with normal serum acetylcholinesterase, 3 cases with mild serum acetylcholinesterase and 1 with severe acetylcholinesterase deficiency required mechanical ventilator assistance. However none of the patient with moderate serum acetylcholinesterase deficiency required ventilator assistance. (Table: 5)

Table 5. AChE_Category vs Ventilator_Assist

\begin{tabular}{|c|c|c|c|c|}
\hline \multirow{2}{*}{\multicolumn{2}{|c|}{ AChE_Category }} & \multicolumn{2}{|c|}{ Ventilator_Assist } & \multirow[t]{2}{*}{ Total } \\
\hline & & 1.00 & 2.00 & \\
\hline \multirow[t]{2}{*}{\begin{tabular}{l|l} 
& 1.00
\end{tabular}} & Count & 1 & 29 & 30 \\
\hline & $\begin{array}{l}\% \text { within } \\
\text { AChE_Category }\end{array}$ & $3.3 \%$ & $96.7 \%$ & $100.0 \%$ \\
\hline \multirow[t]{2}{*}{2.00} & Count & 3 & 11 & 14 \\
\hline & $\begin{array}{l}\% \text { within } \\
\text { AChE_Category }\end{array}$ & $21.4 \%$ & $78.6 \%$ & $100.0 \%$ \\
\hline \multirow[t]{2}{*}{3.00} & Count & 0 & 2 & 2 \\
\hline & $\begin{array}{l}\text { \% within } \\
\text { AChE_Category }\end{array}$ & $0.0 \%$ & $100.0 \%$ & $100.0 \%$ \\
\hline \multirow[t]{2}{*}{4.00} & Count & 1 & 3 & 4 \\
\hline & $\begin{array}{l}\% \text { within } \\
\text { AChE_Category }\end{array}$ & $25.0 \%$ & $75.0 \%$ & $100.0 \%$ \\
\hline \multirow[t]{2}{*}{ Total } & Count & 5 & 45 & 50 \\
\hline & $\begin{array}{l}\% \text { within } \\
\text { AChE_Category }\end{array}$ & $10.0 \%$ & $90.0 \%$ & \\
\hline
\end{tabular}

After initial examination, stabilization and investigation cases were admitted in related wards and managed with appropriate drugs and other supportive measures. Nineteen cases had a total duration of hospital stay in the range of 3-6 days. Among them 16 were from normal, 2 from mild and 1 from severe acetylcholinesterase deficiency group. Likewise 20 cases were admitted for the 
duration of 7-10 days (10 cases from normal, 8 cases from mild and 2 cases from moderate serum acetylcholinesterase deficiency group). Similarly 4 cases from normal, 3 cases from mild, and 3 cases from severe serum acetylcholinesterase deficiency group were admitted for 11-14 days.(Table: 6) Significant relation between initial serum acetylcholinesterase level and total duration of hospital stay was found with $\mathrm{p}$ - value of $<0.05$.

Table 6. AChE_Category vs Duration of hospital stay

\begin{tabular}{|c|c|c|c|c|c|c|}
\hline \multirow{2}{*}{\multicolumn{2}{|c|}{ AChE_Category }} & \multicolumn{4}{|c|}{ Duration of hospital stay(days) } & \multirow[t]{2}{*}{ Total } \\
\hline & & $3-6$ & $7-10$ & 11-14 & 15-18 & \\
\hline \multirow[t]{2}{*}{ normal } & Count & 16 & 10 & 4 & 0 & 30 \\
\hline & $\%$ within AChE_Category & $53.3 \%$ & $33.3 \%$ & $13.3 \%$ & $0.0 \%$ & $100.0 \%$ \\
\hline \multirow[t]{2}{*}{ mild } & Count & 2 & 8 & 3 & 1 & 14 \\
\hline & $\%$ within AChE_Category & $14.3 \%$ & $57.1 \%$ & $21.4 \%$ & $7.1 \%$ & $100.0 \%$ \\
\hline \multirow[t]{2}{*}{ moderate } & Count & 0 & 2 & 0 & 0 & 2 \\
\hline & $\%$ within AChE_Category & $0.0 \%$ & $100.0 \%$ & $0.0 \%$ & $0.0 \%$ & $100.0 \%$ \\
\hline \multirow[t]{2}{*}{ severe } & Count & 1 & 0 & 3 & 0 & 4 \\
\hline & $\%$ within AChE_Category & $25.0 \%$ & $0.0 \%$ & $75.0 \%$ & $0.0 \%$ & $100.0 \%$ \\
\hline \multirow[t]{2}{*}{ Total } & Count & 19 & 20 & 10 & 1 & 50 \\
\hline & $\%$ within AChE_Category & $38.0 \%$ & $40.0 \%$ & $20.0 \%$ & $2.0 \%$ & $100.0 \%$ \\
\hline
\end{tabular}

In our study the final outcomes were measured in terms of discharge and mortality. Among 50 cases 48 cases discharged in optimum state of health after treatment of poisoning while 2 cases expired
(Table 7). No significant relation between initial serum level of acetylcholinesterase and outcome was observed in our study with p- value of $>0.05$.

\begin{tabular}{|c|c|c|c|c|}
\hline \multirow{2}{*}{\multicolumn{2}{|c|}{ AChE_Category }} & \multicolumn{2}{|l|}{ Outcome } & \multirow[t]{2}{*}{ Total } \\
\hline & & Discharged & Mortality & \\
\hline \multirow[t]{2}{*}{ Normal } & Count & 29 & 1 & 30 \\
\hline & $\%$ within & $96.7 \%$ & $3.3 \%$ & $100.0 \%$ \\
\hline \multirow[t]{2}{*}{ Mild } & Count & 14 & 0 & 14 \\
\hline & $\%$ within & $100.0 \%$ & $0.0 \%$ & $100.0 \%$ \\
\hline \multirow[t]{2}{*}{ Moderate } & Count & 2 & 0 & 2 \\
\hline & $\%$ within & $100.0 \%$ & $0.0 \%$ & $100.0 \%$ \\
\hline \multirow[t]{2}{*}{ Severe } & Count & 3 & 1 & 4 \\
\hline & $\%$ within $\mathrm{A}$ & $75.0 \%$ & $25.0 \%$ & $100.0 \%$ \\
\hline \multirow[t]{2}{*}{ Total } & Count & 48 & 2 & 50 \\
\hline & $\%$ within & $96.0 \%$ & $4.0 \%$ & $100.0 \%$ \\
\hline
\end{tabular}

\section{DISCUSSION}

Organophosphate poisoning has been one of the most common modes of self harm and suicide in Nepal for many years. Of the various agents abused with the intention of self harm, OP compounds form a significant group. Various studies done at several different centers support this finding. 5 .6 One of the study done at Kathmandu medical college teaching hospital during 2003 revealed that the prime misused compound was organophosphate in self poisoning cases. ${ }^{7}$ Similar studies at Bir hospital and Patan hospital also revealed similar findings. ${ }^{8}$ A retrospective analysis of poisoning cases during the year of 1994 to 1997 at B.P. Koirala institute of health science showed $47 \%$ of the patients had consumed OP compounds. ${ }^{8}$ Likewise similar findings have been observed from other developing countries also. ${ }^{9}$

Most of the study subjects were young adults of productive age group (15-35 year). Similar to our study different studies also revealed similar findings. ${ }^{6,10,11}$ Young adults with history of OP poisoning has also been reported by Singh D and Acharya $\mathrm{R}$ et al. ${ }^{12}$ This finding might be due to job dissatisfaction, unemployment, poverty and unhealthy relationship among young couples. ${ }^{13}$ Our study also pointed the vulnerability of females over males to self poisoning. This was similar to the study report of Singh D.P et al., and Karki P et al. ${ }^{6,11}$ However with advancing ages this pattern of female to male ratio was reversed 
and number of males attempting to self harming were increased which was similar to the finding observed in the study by Gyawali KK. ${ }^{14}$

Housewives, students and businessmen were the most common group of patients in our study. This finding was similar with other studies done across the country. ${ }^{15,16}$ But it was in contrast to the result of previous study done in KUMS hospital where farmers were the second most common group involved after house wife. ${ }^{17}$ However, farmers were not even in the top three occupational groups of OP poisoning. These results might be due to sustained stress in housewives regarding child care, financial management and domestic violence. Farmers not being in the top three groups may be due to availability of care in areas far from the capital centre.

In this study the majority of cases ingested chlorpyriphos $50 \%$ + cypermethrin $5 \%$ (>50 \% cases followed by dichlorvos $85 \%$ and cypermethrin plains). These agents are widely used as pesticides nowadays. This finding was in contrast to other studies done within the country Nepal in which parathion (metacid) and dichlorvos were most commonly used. ${ }^{10}$ However in this study, the second most commonly ingested compound was dichlorvos. There was no accidental poisoning. Mortality rates were different in different studies done inside our country and abroad ranging from 3.89 to $14 \%$ in studies done inside Nepal .Worldwide studies report mortality rates from $3 \%$ to $30 \% .{ }^{16}$ This study reported mortality of $4 \%$. This may be due to improving standards in OP management. Most common presenting signs/symptoms in our studies were salivation, bronchorrhea, crepitation, increased respiration rate, miosis, urinary incontinence, bradycardia. Some of the findings like bradycardia, salivation, miosis were consistent with other studies done in Nepal. ${ }^{13}$ Seizure, muscle fasciculation and confusion were infrequent findings in most of the cases. ${ }^{18}$ In this study muscle fasciculations, confusion, and seizures were found in $14 \%$, $14 \%$ and $4 \%$ respectively.

In this study there was no significant relation between initial serum acetylcholinesterase level and mortality outcome. Similar finding was observed in a study done by Nouria Semir et al. ${ }^{4}$ In contrast to this study, there was positive relation between initial serum acetylcholinesterase level and mortality outcome in the studies. ${ }^{3,19}$ In the same way, there was no relation between initial serum acetylcholinesterase level and need of mechanical ventilator. ${ }^{20}$ In contrast to this finding ,there was association between initial serum acetylcholinesterase level and need of mechanical ventilator in a study done by Arti Muley et al. ${ }^{19}$ and Soni et al. ${ }^{21}$ This result might had been due to the increased number of severe OP cases in the study. In this study we found positive correlation between initial severity of serum acetylcholinesterase level and duration of hospital stay. Similar result was found in the study done for prognostic values of serum acetylcholinesterase level by Arti Muley et al. ${ }^{19}$

\section{CONCLUSIONS}

OP poisoning was common in young adults of 15- 35 age group with female predominance. Chlorpyriphos $50 \%+$ cypermethrin $5 \%$ was the common compound used followed by dichlorvos. Severity of serum acetylcholinesterase deficiency had a significant correlation with the duration of hospital stay, total atropinization dose, and arrival time from ingestion of poison to hospital. However, there was no significant correlation between serum acetylcholinesterase level and the clinical outcome and need of mechanical ventilator.

\section{Acknowledgement: None}

Conflict of Interest: None

Source of Funding: None 
Ethical Approval: Approved

\section{REFERENCES}

1. Chaudhary S, Kalmegh R. Study of role of prognostic markers in the management of organophosphorus poisoning patients. International Journal of Research in Medical Sciences. 2018 May 25;6(6):1996-9.

2. Paudyal BP. Organophosphorus poisoning. JNMA J Nepal Med Assoc. 2008 Dec;47(172):251-8.

3. Sen, R., Nayak, J. and Khadanga, S., 2014. Study of serum cholinesterase, $\mathrm{CPK}$ and $\mathrm{LDH}$ as prognostic biomarkers in organophosphorus poisoning. International Journal of Medical Research and Review, 2(3), pp.185-189

4. Nouira, S., Abroug, F., Elatrous, S., Boujdaria, R. and Bouchoucha, S., 1994. Prognostic Value of Serum Cholinesterase in Organophosphate Poisoning. Chest, 106(6), pp.1811-1814.

5. Bhattarai N, Rauniyar A, Chaudhary D, Jaiswal S, Banthia P, Rana BB. Patterns of organophosphorus poisoning attending a teaching hospital. JNMA J Nepal Med Assoc. 2006 AprJun;45(162):228-32. PMID: 17189966.

6. Singh DP, Acharya RP. Patterns of poisoning in Nepal. J Inst Med. 2006; 28:3-6.

7. Joshi SK. Pesticides poisoning in Nepal. Kathmandu University medical journal (KUMJ). 2003 Jul 1;1:157.

8. Paudyal BP. Poisoning: pattern and profile of admitted cases in a hospital in central Nepal. JNMA J Nepal Med Assoc. 2005 Sep;44(159):92-6.

9. Abdollahi M, Jalali N, Sabzevari O, Hoseini R, Ghanea T. A Retrospective Study of Poisoning in Tehran. Journal of Toxicology: Clinical Toxicology. 1997 Jan 1;35(4):387-93.

10. Gaire D, Mandal L, Shrestha S. Sociodemographic Profile of Organophosphorus Poisoning Case In A Tertiary Care Hospital Of Nepal. PMJN 2016;16(1)
11. Karki P, Ansari JA, Bhandary S, Koirala S. Cardiac and electrocardiographical manifestations of acute organophosphate poisoning. Singap Med J. 2004;45(8): 385-9.

12. Singh, D., \& Aacharya, R. (2007). Pattern of Poisoning Cases in Bir Hospital. Journal of Institute of Medicine Nepal, 28(1), 3-6. Retrieved from

https://www.nepjol.info/index.php/JIO M/article/view/426

13. Bhattarai MD, Singh DL, Chalise BS, Koirala P. A case report and overview of organophosphate (OP) poisoning. Kathmandu Univ Med J (KUMJ). 2006;4(1):100-4.

14. Kafle KK, Gyawali KK. Organophosphorus- Commonest Poisoning Agent. J Inst Med 1992; 14 : 228-33.

15. Gyenwali D, Vaidya A, Tiwari S, Khatiwada P, Lamsal DR, Giri S. Pesticide poisoning in Chitwan, Nepal: a descriptive epidemiological study. BMC Public Health. 2017 Jul 3;17(1):619.

16. Mandal RK, Daha SK. Clinical and Epidemiological Profile of COVID-19 Patients at a Tertiary Care Center of Nepal: A Retrospective Observational Study. International Journal of Innovative Science and Research Technology (IJISRT). 2021; 6(5): 107378.

17. Marahatta SB, Singh J, Shrestha R, Koju R. Poisoning cases attending emergency department in Dhulikhel HospitalKathmandu University Teaching Hospital. Kathmandu Univ Med J (KUMJ)

18. Peter J, Sudarsan T, Moran J. Clinical features of organophosphate poisoning: A review of different classification systems and approaches. Indian Journal of Critical Care Medicine. 2014;18(11):735-745.

19. Muley A, Shah C, Lakhani J, Bapna M, Mehta J. To identify morbidity and mortality predictors in acute organophosphate poisoning. Indian 
Journal of Critical Care Medicine. 2014; 18(5):297-300.

20. Dilli Ram Sharma. Status of Chemical pesticides use and their regulation in Nepal. http://npponepal.gov.np/uploads/files/St atus $\% 20$ of $\% 20$ Chemical\%20Pesticides $\% 20$ and $\% 20$ their\%20use\%20Dr\%20Dilli\%20Ram\%20Sharma.p df
21. Soni P, Solu MG, Garg V, Pathria A, Shah S, Mundra A. Organophosphate poisoning predicting the need for mechanical ventilator support. International journal of scientific study. 2016;4(6): 168-172.

How to cite this article: Sah AR, Mandal RK. Prognostic value of serum cholinesterase in acute organophosphate poisoning. Int $J$ Health Sci Res. 2022; 12(2): 125-131. DOI: https:// doi.org/10.52403/ijhsr.20220217 